1. Title page

\title{
Leopard density estimates from semi-desert commercial farmlands, southwest Namibia
}

Sarah Edwards ${ }^{* 1,2}$, Ortwin Aschenborn ${ }^{3}$, Alan C. Gange ${ }^{2}$, Ingrid Wiesel ${ }^{1,4}$

${ }^{1}$ Brown Hyena Research Project, P.O. Box 739,Luderitz, Namibia.

${ }^{2}$ School of Biological Sciences, Royal Holloway, University of London, Egham Hill, Egham, Surrey, TW20 0EX, UK.

${ }^{3}$ Ministry of Environment and Tourism, Windhoek, Namibia

${ }^{4}$ Centre for Wildlife Management, University of Pretoria, Pretoria, South Africa.

Email addresses:

Sarah Edwards: hyenaconflict@gmail.com

Ortwin Aschenborn: ortwin@aschenborn.com

Alan Gange: A.Gange@rhul.ac.uk

Ingrid Wiesel: strandwolf@iway.na

*Correspondence: Sarah Edwards, Brown Hyena Research Project, P.O. Box 739, Luderitz, Namibia. Tel. +264 (0) 63 202114. Email: hyenaconflict@gmail.com

Number of words: 1000 


\section{Introduction}

Protected areas are acknowledged as largely inadequate for the conservation of many carnivores (Kent $\&$ Hills 2013). As a result non-protected areas such as farmland are increasingly recognised as important habitats for numerous species (Smith et al. 2011). In some areas carnivore density has been found to be higher outside of protected areas, for example leopard density was significantly higher on farmland in north central Namibia than the bordering Waterberg Plateau Park (Stein et al. 2011a).

Farmlands in southern Namibia represent an unknown area on carnivore distribution maps, and have the potential to be suitable habitat for leopards, given the artificially high density of water sources and herbivore abundance. However at the same time they are largely unsafe environments due to conflict with humans (Henschel et al. 2008). We used camera traps to produce the first leopard density estimates for commercial farmlands in southern Namibia. Additionally, to examine the efficiency of questionnaires for assessing population status, we asked farmers to estimate leopard numbers on their land for comparison. 


\section{Materials and Methods}

The study was conducted across five commercial farmlands (Fig. 1) bordering the eastern boundaries of the Tsau//Khaeb (Sperrgebiet) or Namib-Naukluft National Parks, Karas region, southern Namibia. Main farming activities were livestock production of either sheep Ovis aries, cattle Bos taurus or game (oryx Oryx gazella and springbok Antidorcas marsupalis). Density of artificial water points differed between the two sites (north $=1.85 / 100 \mathrm{~km}^{2}$, south $=5.44 / 100 \mathrm{~km}^{2}$ ). During the study farmers were asked to estimate the number of leopards on their property.

Fifty one camera trap stations were set up at natural and artificial water sources (north $n=2$, south $n=13$ ), and along game trails and roads (north $n=19$, south $n=17$ ) spaced $3.5-4 \mathrm{~km}$ apart. Number of traps were proportional to study site size. Stations at water consisted of a Scoutguard SG560V (HCO Outdoors, Georgia, USA) mounted in a wire cage. Scoutguards were programmed to take one photo per trigger with a minute delay at normal sensitivity. Stations along roads consisted of two Reconyx HC600 (Reconyx Inc, Holeman, Wisconsin, USA) opposite each other. Reconyx took five photos per trigger, with no delay and medium sensitivity.

Following recommendations of Karanth and Nichols (1998), a survey length of 60 days (29th May - 28th July 2013) was used, which should meet the demographic closure assumption. Adult leopard images were identified to individual using pelage patterns. Images where identity could not be confirmed were discarded (north $n=2$, south $n=3$ ). Individual capture histories were constructed, using each day as a sampling period in a standard X-matrix format, and entered into programme CAPTURE (Rexstadt and Burnham 1991). Density was estimated by placing a buffer with radius equal to the half mean maximum distance moved (1/2MMDM) by recaptured individuals to calculate the area covered by camera traps. 


\section{Results}

A total of 28 identifiable leopard images were captured across the two sites (Table 1). Three adult individuals were detected at the northern sites, whilst five individuals were recorded in the south, not all individuals were recaptured. CAPTURE suggested the best models to be heterogeneity (Mh) for the northern sites and the null model (Mo) for the southern sites, and estimated 4 ( $S E=1.15,95 \%$ $\mathrm{Cl} 4-11)$ and 5 ( $\mathrm{SE}=0.41,95 \% \mathrm{Cl} 5-5$ ) at the northern and southern sites respectively. 1/2MMDM varied between the two sites; at the northern sites a distance of $4.3 \mathrm{~km}$ covered a total of 428.92 $\mathrm{km}^{2}$ producing a density of 0.9 leopards $/ 100 \mathrm{~km}^{2}$, whilst a $1 / 2$ MMDM of $6.88 \mathrm{~km}$ at the southern sites covered an area of $852.01 \mathrm{~km}^{2}$ producing a density of 0.59 leopards $/ 100 \mathrm{~km}^{2}$. Accuracy of farmer estimates of leopard numbers compared to the number generated by camera trap data varied between farmers (Fig. 2). 


\section{Discussion}

A mean leopard density of 1.2 leopards $/ 100 \mathrm{~km}^{2}$ is categorised as low in Namibia (Stein et al. 2011b), and our results from both sites are even lower. This is not surprising given that sub-Saharan leopard density is positively correlated with rainfall (Martin \& de Meulanaer 1988), with arid conditions producing low density populations with large home ranges (Mizutani \& Jewell 1998). Our results are similar to density estimates from other arid areas; $1.0 / 100 \mathrm{~km}^{2}$ on commercial farmlands north central Namibia (Stein et al. 2011a), 1.3/100 km² in the Kalahari (Bothma \& Le Riche 1984), and 1.5/100 $\mathrm{km}^{2}$ north eastern Namibia (Stander et al. 1997).

Foster and Harmsen (2012) noted small sample sizes and limited recaptures are associated with low precision. The northern estimate showed relatively wide $95 \%$ confidence intervals of 4 11 individuals, which using the lower and upper limits would produce density estimates in both the low and medium density categories of Stein et al. (2011b). Such a range could be due to the fact not all individuals were recaptured. As an alternative Foster and Harmsen (2012) suggest reporting the minimum number alive, which would produce lower density estimates for the northern sites $\left(0.70 / 100 \mathrm{~km}^{2}\right)$, although the southern estimate would remain the same.

Differences in density estimates between sites may have reflected methodological differences. As the northern site was smaller and used less camera traps, less area was covered meaning the smaller $1 / 2 \mathrm{MMDM}$ calculated and higher density could reflect methodological differences between the study sites. Additionally due to the lower water density in the north, less water points were monitored than in the south, here capture frequency at water points was much higher at water (12.59), than on trails (0.82).

Questionnaires are a commonly used tool for assessing population status and humanwildlife conflict, however concerns exist regarding the usefulness of this practice over deliberate over-inflation and inaccuracy (Hermann and Funston 2001). Our results show variation in the accuracy of farmer estimates of leopard numbers compared to numbers detected by camera trap. One farmer estimated over five times the number of leopards detected, whilst another was relatively accurate. Our results would further question the use of the questionnaire in lieu of field work, and the suitability of using such data gained in management practices. 


\section{Acknowledgments}

This project was funded by Nedbank Go Green Fund, Namdeb Diamond Corporation and Royal Holloway University of London to whom we thank. Thanks also to Ministry of Environment and Tourism, all participating landowners and research assistants, and an anonymous reviewer who improved the quality of this manuscript. 


\section{References}

Bothma, J.\& Le Riche, E.A.N. (1984). Aspects of the ecology and behaviour of the leopard Panthera pardus in the Kalahari Desert. Koedoe 27, 259-279.

Foster, R. J. \& Harmsen, B. J. (2012). A critique of density estimation from camera-trap data. J. Wildl. Manage. 76, 224-236.

Henschel, P., Hunter, L., Breitenmoser, U., Purchase, N., Packer, C., Khorozyan, I., Bauer, H., Marker, L., Sogbohossou, E. \& Breitenmoser-Wursten, C. (2008). Panthera pardus. The IUCN Red List of Threatened Species. Version 2014.1. www.iucnredlist.org [July 2014].

Herrmann, E., Funston, P., \& Babupi, P. (2001). A questionnaire-based survey of farming areas surrounding the Kgalagadi Transfrontier Park: The extent of conflict between large carnivores and domestic livestock. In Population-ecology and long term monitoring of a free-ranging population in an arid environment. Funston, P. J. ed. 107-136. (pp. 107-136).

Karanth, K. U. \& J. D. Nichols. (1998). Estimation of tiger densities in India using photographic captures and recaptures. Ecology 79, 2852-2862.

Kent, V. T. \& Hill, R. A. (2013). The importance of farmland for the conservation of the brown hyaena Parahyaena brunnea. Oryx 47, 431-440.

Martin, R.B. \& du Meulenaer, T. (1988). Survey of the status of the leopard (Panthera pardus) in subSaharan Africa. CITES, Switzerland.

Mizutani, F.A. \& Jewell, P.A. (1998). Home-range and movements of leopards (Panthera pardus) on a livestock ranch in Kenya. J. Zool. 244, 269-286.

Rexstadt, E. \& Burnham, K.P. (1991). User's guide for interactive program CAPTURE. Abundance estimates for closed populations. Colarado State University, USA.

Smith, R. K., Ryan, E., Morley, E. \& Hill, R. A. (2011). Resolving management conflicts: Could agricultural land provide the answer for an endangered species in a habitat classified as a World Heritage site? Environ. Conserv. 38, 325-333.

Stander, P. E., Haden, P. J., Kaqece, I. \& Ghau, I. (1997). The ecology of asociality in Namibian leopards. J. Zool. 242, 343-364.

Stein, A., Andreas, A., Aschenborn, O., Kastern, M., Andreas, A. \& Thompson, S. (2011b). Namibian national leopard survey 2011 final report. Namibia: Ministry of Environment and Tourism Internal Report.

Stein, A. B., Fuller, T. K., Destefano, S. \& Marker, L. L. (2011a). Leopard population and home range estimates in north-central Namibia. Afr. J. Ecol. 49, 383-387. 
8. Tables

Table 1: Leopard Density estimates from commercial farmlands, southwest Namibia

\begin{tabular}{|c|c|c|c|c|c|c|c|c|c|c|c|}
\hline Site & $\begin{array}{l}\text { \# leopards } \\
\text { captured }\end{array}$ & $\begin{array}{l}\# \\
\text { recaptures }\end{array}$ & $\begin{array}{l}\text { Mean } \\
\text { capture } \\
\text { freq.* }\end{array}$ & $\begin{array}{l}\text { Range } \\
\text { capture } \\
\text { freq.* }\end{array}$ & Model & $\begin{array}{l}\text { Abundance } \\
\text { (S.E) }\end{array}$ & $\begin{array}{l}95 \% \\
\mathrm{Cl}\end{array}$ & $\begin{array}{l}\text { 1/2MMDM } \\
(\mathrm{km})\end{array}$ & $\begin{array}{l}\text { Total } \\
\text { Area/km }\end{array}$ & $\begin{array}{l}\text { Density }(\# \\
\left.\text { adults } / 100 \mathrm{~km}^{2}\right)\end{array}$ & $\begin{array}{l}\text { Density - } \\
\text { min. \# } \\
\text { alive } \\
\left(\# / 100 \mathrm{~km}^{2}\right)\end{array}$ \\
\hline North & 3 & 7 & 29 & $12-60$ & $\mathrm{Mh}$ & $4(1.15)$ & $4-11$ & 4.3 & 428.92 & 0.9 & 0.70 \\
\hline
\end{tabular}

*freq. of capture refers to the mean number of camera traps nights per event for each individual 


\section{Figure legends}

Figure 1: Location of study sites in southern Namibia

Figure 2: Comparison of leopard density estimates from CAPTURE and farmers, commercial farmlands, southwest Namibia. The fifth farmer could not estimate leopard numbers on his land. 


\section{Figures}

Figure 1

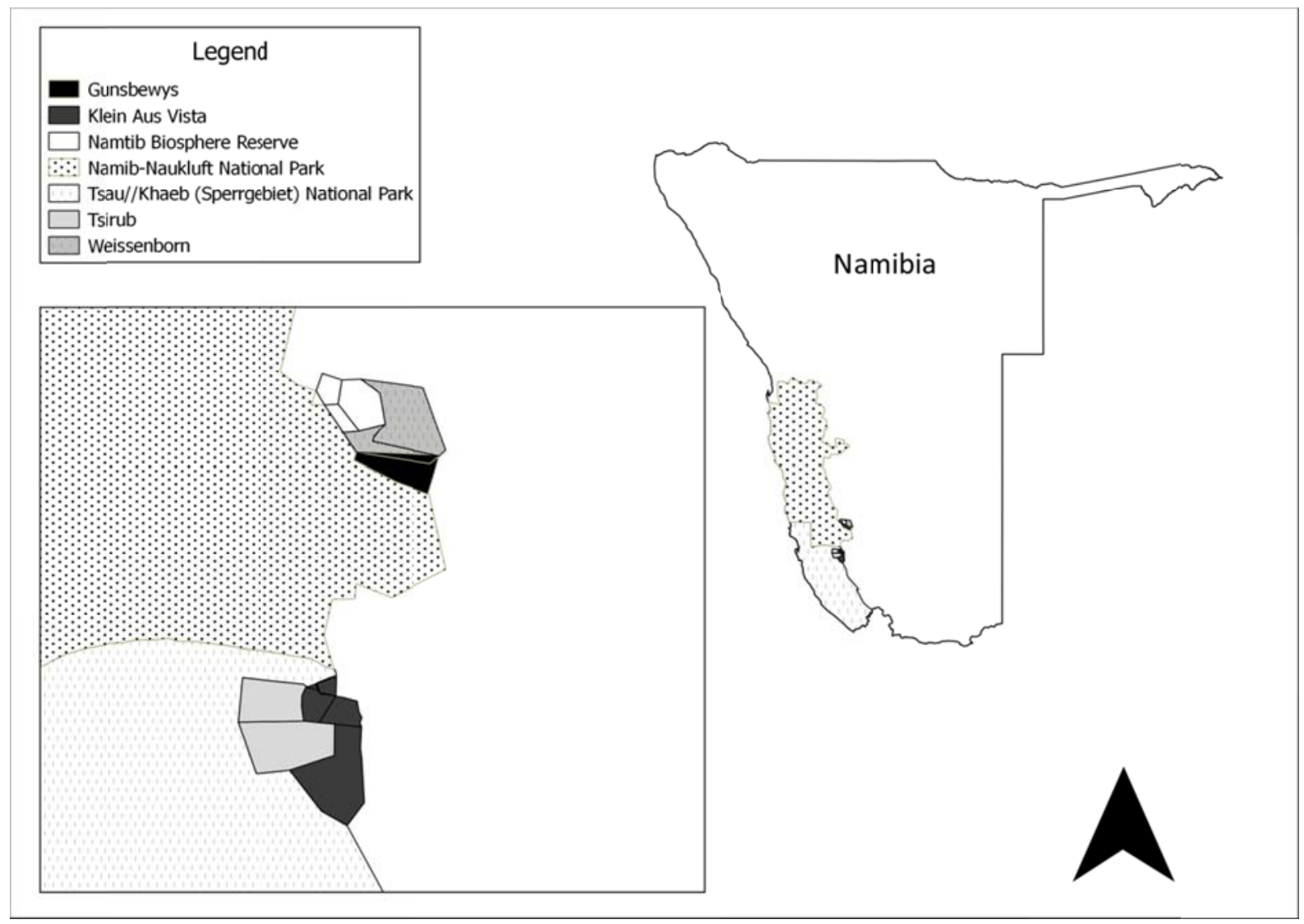

Figure 2

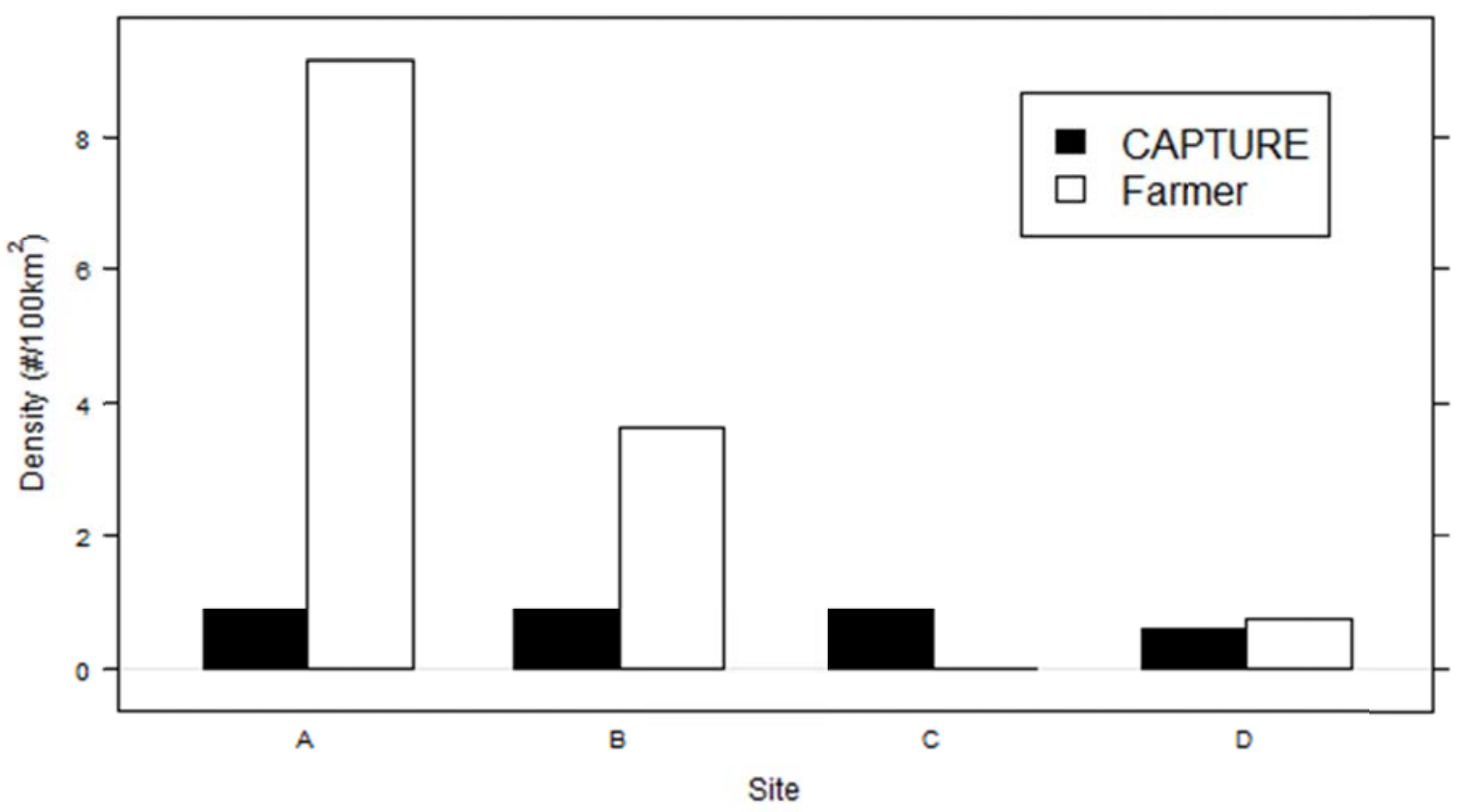

